\title{
Chapter 7 \\ The Epistemic Importance of Novices: How Undergraduate Students Contribute to Engineering Laboratory Communities
}

\author{
Caitlin Donahue Wylie
}

Scholars and practitioners have long viewed learners as works-in-progress, as somewhat empty vessels to be filled with appropriate knowledge and skills to become future practitioners. A variety of powerful critiques portray this mindset as inaccurate and a barrier to effective learning and identity formation (e.g., Jones and Brader-Araje 2002; Wilson and Peterson 2006; Duschinsky 2012). These authors argue for embracing learners' existing knowledge and identities to facilitate their learning and also to enable their perspectives to inform a community's existing knowledge (e.g., Hakkarainen et al. 2004).

However, some communities continue to talk about novices according to the old model of passive receivers of knowledge. For example, academic research groups in engineering tend to assume that expertise aligns with hierarchy, such that higherstatus members (e.g., faculty, graduate students) have more valuable knowledge than lower-status members (e.g., undergraduate students). This study challenges that view by presenting evidence that social and technical knowledge does not only flow from supposed experts to supposed novices; rather, it circulates and changes as it travels between them. What, then, do the identities of "expert" and "novice" mean in practice?

Based on participant observation and interviews in two engineering research laboratories in an American university, I argue that it is more productive to define a community based on mutual learning rather than a hierarchy of experts. Similarly, sociologists Grit Laudel and Jochen Gläser define scientific identities based on whether the person is learning or teaching: "An apprentice learns to conduct research while working under the direction of others; a colleague conducts independent research and contributes the results to the community's knowledge; a master is a colleague who additionally acts as a mentor for apprentices" (2008, p. 390, original

\footnotetext{
C. D. Wylie $(\triangle)$

Program in Science, Technology, and Society, University of Virginia, Charlottesville, VA, USA e-mail: wylie@virginia.edu
} 
emphasis). However, while these roles hold true in some situations, I found that lab members regularly swap the roles of learner and instructor, regardless of their status as an undergraduate student, a graduate student, or a faculty member/principal investigator (PI). Status does matters, though, because identity relies on how individuals perceive themselves as well as how others treat them; identity is therefore "double sided" (Stevens et al. 2008, p. 357, drawing on concepts of identity and the self from Holland et al. 1998). For example, lab members might be surprised if undergraduates demonstrate expertise about a topic because they assume students are primarily learners, even if those students consider themselves experts about that topic. Likewise, PIs are likely to consider themselves experts in their discipline, though of course they continue to learn. Thus, the identities of "PI" and "student" do not always predict which members teach and learn.

In particular, I found that undergraduates play a wider variety of roles in research communities than scholars and practitioners realize. Lab members' perceptions of undergraduates grant these students unique opportunities to shape knowledge construction. Specifically, lab members perceive undergraduates, as a category of both ascribed and achieved identity, as low-status, low-stakes learners as well as interdisciplinary, open-minded scholars. These roles enable undergraduates to actively contribute to the construction of knowledge and communities by serving as local experts at lab tasks and as non-expert outsiders who challenge the knowledge that lab members take for granted. Thus, students - and all lab members - play the roles of expert and novice depending on the situation. These roles are not strictly tied to members' more stable identities as undergraduates, graduate students, or PIs. One benefit of this fluidity is that students can more easily develop an identity as a member of a research community if they are actively contributing as well as gaining knowledge.

Novices, such as apprentices, construct their professional identity through experiences with a community (Lave and Wenger 1991). Novices bring their own backgrounds and future aspirations, which must be included in a learning process to create a "trajectory"- a sense of context and purpose for learning that then shapes novices' identities (Wenger 1998, p. 154). But communities often reject novices' knowledge as "marginal" and irrelevant to their own practices and beliefs (Wenger 1998, p. 216). Novices look like empty vessels indeed when the community doesn't recognize their past experiences as valuable. Novices then may struggle to develop a sense of trajectory and thus identity in the community. Education scholar Etienne Wenger criticizes this approach as not only discouraging potential future members but also overlooking "a wisdom of peripherality"- the insights about a community and its practices that are available only to relative outsiders (1998, p. 216). By revising communities' view of knowledge to be diffuse rather than centralized in the most experienced or highest-status members, we gain novices' important perspectives while also supporting their formation of trajectory and identity. Communities will still marginalize novices, due to their insufficient expertise or what Wenger calls "competence" (1998, p. 216). But embracing novices' view from the periphery would promote their identity formation and success in the community and improve learning for all members, thereby strengthening the community's current practices and future population. By shifting between the roles 
of expert (e.g., instructor) and novice (e.g., learner), all members develop a sense of the knowledge that they can teach and learn from others.

To represent the epistemic exchanges between novices and experts, I propose a model of community interactions as a system of transfers of ideas between community members with different identities (e.g., PIs, graduate students, and undergraduates). These exchanges simultaneously build identities and communities. Research communities typically define their primary output as knowledge, not new practitioners. But Wenger (1998, p. 214) suggests that a "community of practice"-in which novices participate alongside experts-is a powerful site of knowledge creation because of the dynamism of novice-expert interactions. I suggest that applying Wenger's view of learning as the central activity of research communities will help us understand how these communities produce new members as a mechanism of creating new knowledge. To acquire expertise, after all, everyone must learn and continue to learn; expert skills and knowledge are not static. As novices learn, they help other members learn too. Therefore, studying novices, as the community members who focus the most explicitly on learning, provides a window into how people change their own and their community's knowledge. First I situate this study among theories about initiation into technoscientific communities, then I discuss how novices' expertise and inexpertise both benefit these communities.

\subsection{The Roles of Novices in Communities}

Existing models of how communities incorporate novices focus on the reproduction of the community more than on novices' existing attributes or values, by assuming that successful novices will perpetuate established ways of doing and knowing (Mody and Kaiser 2008, pp. 379-81). Learning these norms relies on the process of socialization, i.e., adapting a newcomer to a group's practices and behavior. For example, physician and philosopher Ludwik Fleck focuses on a student's mastery of a community's thought style as the key part of indoctrination into a scientific community, such that "[a thought style] becomes natural and, like breathing, almost unconscious, as a result of education and training as well as through his participation in the communication of thoughts within his collective" (1979, p. 141). Fleck does not consider novices' existing identities or beliefs, except by assuming that they will be replaced with that of the collective.

According to Fleck, learning what a collective believes and how members think is more important for a novice than learning hands-on practices or, implicitly, merging a novice's own beliefs with the collective's. For example, Fleck presents textbooks as the primary mode of learning a thought style and thereby joining a thought collective (1979, p. 112). He defines a thought style as a result of "authoritarian" instruction (1979, p. 104), in that "any didactic introduction to a field of knowledge passes through a period during which purely dogmatic teaching is dominant" (1979, p. 54). There is no mention of how students align this "dogmatic" education with their existing knowledge and identities. Philosopher Thomas Kuhn similarly argues that students must learn a scientific field's "paradigm," which includes a thought 
style and accepted knowledge as well as research methodologies (1996, p. 109). Like Fleck, Kuhn credits textbooks as powerful agents of transferring a paradigm to students, though he criticizes the "narrow and rigid education" they provide (1996, p. 166). He omits interacting with colleagues as part of a paradigm or as a way of learning a paradigm. However, textbooks and unquestioned dogma are insufficient for building novices' identities or preparing them to join a research community.

In particular, textbooks cannot convey a community's tacit knowledge, meaning knowledge that is not articulated (Collins and Evans 2007; Kaiser 2005). Research skills, such as the appropriate use of tools and ideas, and social norms rely on tacit knowledge. This is one reason why engineers historically learned their profession through apprenticeship (Calvert 1967). Apprenticeship provides direct instruction and hands-on practice, alongside camaraderie, informal interactions, and feedback when a learner breaks a social or technical norm. Anthropologist Jean Lave and Wenger (1991) argue that group interaction is so embedded in learning that the two cannot be separated. Only through "legitimate peripheral participation" in a "community of practice" can learners gain both the social knowledge and the practical skills required to be accepted as members (Lave and Wenger 1991, p. 29).

Fleck and Lave and Wenger present novices as blank slates by not acknowledging their existing knowledge and experiences. Fleck's thought collective is unidirectional, in that novices are transformed to see through the collective's eyes. However, a thought collective relies on bringing together many people's views, experiences, and questions as they try to make sense of new ideas and evidence. Fleck (1979, p. 144) even claims that thought collectives are egalitarian: "All research workers, as a matter of principle, are regarded as possessing equal rights." These ideas value multiple perspectives and identities, but novices do not seem to qualify as "research workers" to Fleck. Lave and Wenger's idea of a community of practice is similarly top-down, in that novices are immersed alongside expert practitioners. A community of practice pursues "the generative process of producing their own future" by preparing learners as future members (Lave and Wenger 1991, pp. 57-8). Lave and Wenger and their research participants do not consider what novices bring to the community; instead, they portray learners' experiences of being taught to carry on the community's status quo.

In contrast, Kuhn argues that newcomers, such as students, are a common and important cause of paradigm shift, thanks to their incomplete indoctrination into the existing paradigm and thereby their different worldview from more experienced researchers (1996, p. 90). But Kuhn's celebration of novices as an injection of creativity and outside perspectives is only mentioned briefly, and it is not shared by Fleck or Lave and Wenger. Ethnographies have shown the epistemic value of including a variety of scientific — and non-scientific - identities in research communities (e.g., Traweek 1988; Galison 1997; Doing 2009; Wylie 2015a, b, 2016, 2018a), but they do not explore the impact of learners.

A few studies note the contributions of graduate students to research communities. Sociologist Robert Campbell (2003) argues that managing graduate students is an important everyday task of being a scientist, though it is not explicitly taught or highly valued. Students therefore provide scientists with the opportunity to learn how to mentor. Working with students is an example of the "articulation work" of 
making scientific knowledge (Fujimura 1996), alongside organizing resources, communicating with administrators and funders, and other undervalued tasks that make research possible. Graduate students typically do hands-on research work while PIs plan projects and train the students (Felt et al. 2013; Delamont, Atkinson, and Parry 2000; Walford 1981). Education scholar Geoffrey Walford (1983) argues that because graduate students in science perform so much of a research group's work, decreasing their number would reduce most groups' productivity. Thus, student labor outweighs even the significant time and effort invested in training them. Vincent Lariviere (2012), a scholar of information science, found that graduate students who are involved in multiple projects and collaborations tend to be more productive, i.e., they publish more papers and finish their degrees more quickly. These studies consider graduate students as an important workforce but not necessarily as contributors of ideas or community-building. These studies-and most others (e.g., National Academies 2017) — do not mention undergraduates as members of labs or of the broader context of a research community's "epistemic living space" (Felt 2009).

Omitting undergraduates from studies of knowledge production and laboratory life overlooks a segment of the research workforce as well as a source of technical skill and interdisciplinary ideas. For example, graduate students report many personal and professional benefits of mentoring undergraduates, including more productivity, confidence, enjoyment, communication and mentoring skills, and improved comprehension of field-specific knowledge (Dolan and Johnson 2009, pp. 491-2). Teaching undergraduates in courses also improves graduate students' research skills, such as their ability to develop good research questions and study designs (Feldon et al. 2011). These benefits are striking in their variety and importance to graduate students' professional abilities, and they deserve further study.

This paper investigates how novices shape an expert technoscientific community as an exchange rather than a transfer of experts' knowledge and values to novices. This view is especially important now, as movements for interdisciplinary research, citizen science, and technology entrepreneurship celebrate novices' contributions to technoscience. Therefore, I suggest that we think about novices and experts interacting in a community as an interconnected ecosystem, with feedback loops and shifting, situated relationships. Because undergraduates' experiences as lab workers resemble apprenticeships (in terms of active learning, social immersion, identity-building, and mentoring), studying students offers valuable insights into epistemic exchanges between novices and experts.

\subsection{Methodology}

This paper draws from an ethnography of two engineering laboratory communities that include undergraduate workers in a medium-sized public research university in the United States (Wylie 2018b; Wylie 2019; Wylie and Gorman 2018). One PI, 
whom I call Kate, ${ }^{1}$ studies the properties of materials. Kate's lab has one postdoc, nine graduate students, and three undergraduates. Including Kate, nine lab members are women and five are men; this proportion of women is unusually high. ${ }^{2}$ Two lab members belong to racial or ethnic groups that are underrepresented in engineering in the United States, which is a lower proportion than the national averages. ${ }^{3}$ The other lab's PI, whom I call Dan, develops electronic sensor systems. Dan's lab has one postdoc, 11 graduate students, and two undergraduates. Two lab members are women and 13 are men, which is an unusually low proportion of women. One lab member belongs to an underrepresented group, which is also an unusually low proportion. The five undergraduates work for hourly pay and had worked in their labs for at least one term (and up to three years) before this study began. I attended group meetings, shadowed each undergraduate in the lab to observe how they interacted with other members, and interviewed members during the academic year of 2016-2017.

Grounded theory and inductive analysis guided the qualitative data analysis of my observation fieldnotes and interview transcripts (Creswell 2007). I indicate which data are from interviews with citations; all other quotations are from my fieldnotes. The study examines what and how undergraduates learn from working in labs, a question that also yields opportunities to observe the formation of identities and communities in action. In observations I was looking for moments of learning, when knowledge passed between interlocutors explicitly or implicitly. I found significant exchange and construction of knowledge between supposed experts and novices. I sorted these moments of epistemic exchange-i.e., events and statements from fieldnotes and transcripts - by context to understand the circumstances in which they occurred. These data fit two broad categories, explored in the following sections of this paper: situations in which undergraduates are experts and decidedly not experts. These findings capture the epistemically rich benefits of members' movement between the roles of expert and novice in technoscientific communities.

\subsection{Undergraduates' Expertise}

Despite their low status as novices, undergraduates can be research groups' local experts about techniques. The opportunity to share their knowledge grants undergraduates a sense of belonging in the community and a clear contribution to the group's research. According to Kate's graduate student Samuel, "we ask each other

\footnotetext{
${ }^{1}$ All names are pseudonyms.

${ }^{2}$ In 2016 in the United States, women earned only $21 \%$ of engineering undergraduate degrees, $25 \%$ of master's degrees, and 23\% of doctoral degrees (Yoder 2016, pp. 15, 23, 27).

${ }^{3}$ In 2016 in the United States, students from underrepresented racial or ethnic groups earned only $18 \%$ of engineering undergraduate degrees, $16 \%$ of master's degrees, and $13 \%$ of doctoral degrees (Yoder 2016, pp. 15, 23, 27).
} 
for help a lot because everyone's an expert in something" (interview 10). The community benefits from members' sharing of their diverse skills. Psychologists call this collective awareness of each member's specific expertise transactive memory, which is best established through training with a community (Wegner 1986; Gorman 2002). For example, Dan's research group depends on undergraduates Will and Rick to build websites and 3D-print materials, respectively. Both students learned these skills on their own, not from working with Dan's group, and no other member had these skills. Similarly, Kate named undergraduates Jessie and Gretchen as her group's experts with a certain machine thanks to their frequent use of it. Graduate students first trained the two undergraduates to operate the machine, and the undergraduates then honed their skills through trial and error.

The most valuable knowledge and skills undergraduates can have are those that other members lack. For example, undergraduate Elena shared her knowledge of physiology learned from her biomedical engineering major with Dan's research group of electrical and computer engineers. During a meeting, a graduate student was presenting about how electronic sensors measure people's stress. Dan asked whether cortisol levels could indicate stress, and the graduate student didn't know. Dan asked another graduate student, who also didn't know, and clearly neither did Dan. Then Elena spoke up, explaining that cortisol levels change with circadian rhythms and exercise, so they are a nonspecific, problematic indicator of stress. This information inspired a lively discussion among Dan and the graduate students about how to use cortisol level as a "ground truth" for stress, including how to exclude other variables and measure changes with noninvasive sensors. The group needed the undergraduate's knowledge, which she had learned from another discipline. Making connections between disciplines is an important and common contribution from undergraduates, at least in education systems that prioritize general education alongside discipline-specific courses. In the United States, undergraduates take courses in various fields, while PIs' and graduate students' most recent education is specific to their chosen field.

When undergraduates have abilities that others don't, PIs encourage them to share. Undergraduates spend less time in the lab than graduate students do, due to their heavy course load and shorter degree time, so disseminating their skills is important for a research community. For example, Dan asked Rick to present his 3D printing method to the group "so we don't have to rely on just a couple of people for our 3D modeling." Dan asked several questions during Rick's presentation, revealing his own minimal knowledge as well as his eagerness for himself and others to learn. It surprised me that both Will and Rick wanted to teach their skills so that they could stop doing those tasks. Will tried to hand off the group's website management to all new undergraduates, as yet unsuccessfully. Rick had already delegated most 3D-printing work to newer undergraduates because "I've probably learned what I've needed to." Both undergraduates told me they were bored with those tasks and wanted to focus on learning new skills. They did not revel in their mastery, implying that this expert status may not align well with their identities as learners. This desire to learn is important for novices' success in communities. Aversion to mastered 
topics could impede a community's efficient division of labor, though, if members don't want to work on tasks they already know.

Inviting undergraduates to teach recognizes their skills and defines them as valuable community members, thereby building their double-sided identity and their sense of belonging in the research group. For example, Kate asked Gretchen and Jessie to write instructions for the group about experimental procedures they knew well because "I'm always looking for people to pass down their expertise on skills and techniques." She meant "down" to posterity and future lab members, not "down" the hierarchy from PI to graduate student to undergraduate; after all, in this case undergraduates were the instructors. Gretchen and Jessie were happy to oblige, perhaps because they were being treated like experts. Kate even included them on a document she emailed to the group listing each technique next to the names of lab members who know how to do it. Kate is thereby codifying the group's transactive memory and tacit knowledge, making it more explicit and accessible. Accordingly, Kate advised a new graduate student to ask Jessie how to work with a material they both study, indicating Jessie's skill and making Jessie proud. Unlike Rick and Will, Gretchen and Jessie aren't trying to hand off their responsibilities to others. Their skills are newer-acquired in the past year-so it's possible they are not as bored with them as Rick and Will are, after three years each in their research group.

It is interesting that these lab members express no competition. After all, scientists talk about competition with other research groups in their field as a defining feature of their struggle to create an identity for their research group and for themselves as PIs (Hackett 2005). But perhaps members don't compete as strongly within a research group. In these two groups, no one hoards skills for individual benefit or feels threatened that someone might surpass them in these skills. Instead, they appreciate everyone's efforts to acquire skills and share them. Swapping skills makes everyone into learners, not just the novices (who are sometimes the experts).

Another context in which undergraduates are considered experts is regarding the specific tasks they have done. Dan's graduate student Edward said, "Will is teaching me today how to use the system to test the app" that Will had built. Will is arguably the singular expert on this smartphone application because he programmed it. Likewise, Kate's undergraduate Jessie told me about a future paper she would write with graduate student Laurie:

I would have to have a big role in writing that [paper] just because I did the experiment. The theoretical stuff and all of the discussion, the more conceptual stuff, goes over my head a little bit more, but the actual work? That I'm good with. (interview 13)

Jessie believes that Laurie needs her to write about the experiment, as the experimenter. Separately, Laurie told me that undergraduates are "maybe even more practical than some graduate students or [people with] PhDs ... They're just not getting so heavy-handed in the details of the scientific understanding. Sometimes you can be more focused on output and results and progress" as a graduate student, to the detriment of the research (interview 11). Laurie values Jessie's "practical" skills of doing experiments and not getting lost in theories or concerns about research productivity. Laurie can handle the "conceptual stuff," as can any expert in the field, 
but only Jessie knows about "the actual work" of these particular experiments. This local, situated, one-of-a-kind expertise often belongs to undergraduates, as the most hands-on lab workers. Of course, the "theoretical stuff" can't stand alone; it relies on the practitioner's experienced reality of the research.

\subsection{The Epistemic Value of Inexpertise}

In addition to sharing their expertise, novices enable other kinds of epistemic interactions thanks to their identity as non-experts. For example, PIs and graduate students perceive undergraduates as low-stakes learners and broadly-educated, interdisciplinary scholars. Undergraduates take more diverse courses than graduate students do, and they have less experience in the research group's field, making them less indoctrinated. These attributes are why Kuhn (1996, p. 90) credited most paradigm shifts to fields' relative newcomers. Likewise, undergraduates lack graduate students' deep knowledge, although their flexibility and open-mindedness make them capable learners and thinkers. Dan's postdoctoral researcher James explained this difference in terms of identity: "Entering graduate school, [students] may have a self-definition about 'I'm an electrical engineer,' 'I'm an engineer,' 'I'm a doctor.' The undergraduates don't have any definition about themselves. They are open for any kind of things" (interview 2). As a result, for James, "sometimes I prefer more undergraduates instead of grads" in a research group, thanks to undergraduates' broad interests that are not yet restricted by a field-specific identity. Also, lab members assume (often correctly) that undergraduates know little about the group's work. As a result, they offer explanations, invite questions, and listen to undergraduates' sometimes unorthodox ideas. In comparison, PIs and undergraduates expect graduate students to have significant field-specific knowledge. This role grants undergraduates more freedom to learn than graduate students, whose reputation in the community as knowledgeable and professional is more significant for their academic and career success.

\subsubsection{How Low-Stakes Learning Encourages Epistemic Exchange}

Undergraduates' double-sided identity as research novices means that they are encouraged to ask questions, and they often do. PIs also invite questions from graduate students but expect them to know more than undergraduates; therefore, graduate students' questions are more risky for their reputations than are undergraduates'. For example, graduate students might be admonished for asking a "dumb" question, while undergraduates are likely to be forgiven. This grants undergraduates a privileged position as question-askers, which simultaneously provides 
opportunities for graduate students to hear answers to questions they may share but don't ask for fear of looking ignorant. In addition, undergraduates' questions and lack of field-specific knowledge create a demand for PIs and graduate students to explain ideas and instructions, including contextualizing them in terms of what the undergraduates already know. This combination of expertise about a topic and about an audience, known as pedagogical content knowledge, is crucial for effective teaching and communication (Magnusson et al. 1993). Thus, answering novices' questions can improve the answerers' own understanding of concepts and inspire them to think about their knowledge from different perspectives.

Undergraduates can challenge PIs' and graduate students' assumptions by asking seemingly basic questions. Kate's graduate student Laurie, for example, was showing undergraduate Jessie how to use a machine that measures chemical bonds. A graph of measurements popped up on a computer screen, and Laurie rejected it because it had no "peaks." She adjusted a parameter on the machine, explaining to Jessie: "I know from experience there's a lot of noise [i.e., meaningless results]. You want the [graph] lines to be smoother, so upping the power can smooth it out." She ran the analysis with higher power. The new results showed one tall, thin peak which Laurie dismissed, saying, "That's cosmic." Jessie asked, "What was wrong with that one?" Laurie answered absently as she raised the machine's power again, "It's called a cosmic ray. It's not data." She contrasted the cosmic "spikey" peak with a desirable "smoother," "broad" peak. This is a typical example of undergraduates' frequent requests for justification. Explaining tasks requires practitioners to think about how and why they do that work and how to communicate those reasons to non-experts. Philosopher Donald Schön (1987) argues that such "reflection-in-action," i.e., questioning one's own assumptions and routines while enacting them, enables professionals to better identify problems and adapt their practices accordingly. Undergraduates' in-the-moment demands for explanations can thereby challenge assumptions that underlie "normal science" (Kuhn 1996) by inviting graduate students and PIs to recognize their assumptions and potentially revise them (Wylie et al. 2019). For example, which results are data and not data is obvious to Laurie but not to Jessie. Explaining the difference means that Laurie thinks through her judgments, creating an opportunity for error-spotting and new ideas. When not teaching an undergraduate, Laurie probably does not think about why she ignores cosmic rays.

Some research communities value undergraduates as knowledgeable enough to understand the field yet not specialized enough to be mired in isolated conversations with experts. Accordingly, Kate relies on undergraduates to judge the accessibility of graduate students' presentations in lab meetings, precisely for their lack of discipline-specific knowledge. For example, after graduate student Samuel presented a practice conference talk to Kate's research group, he commented that it is targeted at the conference's audience so "it's tough to understand this talk" if you're not an expert. Kate asked Jessie, "How'd it go for you?," thereby making Jessie a test case for whether non-experts could understand Samuel's talk. Jessie rarely speaks in lab meetings, but she did not hesitate to respond to Kate's question. She told Samuel that she understood his results, but the experimental setup "went over my head." She also asked why he used the oxygen isotope $\mathrm{O}_{18}$ instead of the 
more common $\mathrm{O}_{16}$. Kate, impressed, said, "That's a really valuable question. Thank you." The graduate students then discussed where to add the answer to Jessie's isotope question into Samuel's presentation. It's possible an undergraduate could have been scolded for questioning a graduate student's methodological choice. Instead, the non-expert's confusion served as feedback to improve the expert's communication skills. This situation resembles interactional expertise, in that Jessie can talk competently about a field without necessarily contributing to it (i.e., contributory expertise as defined by Collins and Evans [2007]). Graduate students benefit from knowing when their presentations are too specialized and "go over [the] head" of educated generalists such as undergraduates. In response, graduate students acquire widely-applicable communication skills in the form of pedagogical content knowledge-i.e., they learn to recognize concepts that only experts know and to explain them effectively to non-experts.

Although undergraduates' questions can be important for a research community, many go unasked. This is evident from Dan and Kate's ongoing emphasis that students should ask questions, which suggests that they know students sometimes hesitate to ask and thereby publicly reveal their lack of understanding. For example, at one meeting for Dan's group, students discussed a journal paper they had read. Afterwards I asked Will and Rick about a recurring word in the group's discussion: "stochastic." I assumed it was yet another ubiquitous engineering term that I, as a non-engineer, didn't know. But neither undergraduate knew what it meant. Both said they had wondered about it during the meeting, but neither had asked. Will used context to decode the word: "He opposed it to 'deterministic,' so it can't mean that." He mused that it must be about predictability because the paper was about statistics. Rick posed some guesses while Will googled the word on his smartphone, then reported that it means there is some random variability. Will then asked Rick a question about the paper's equations and Rick looked embarrassed, admitting, "I didn't really get the math." This was a missed opportunity. Based on Rick's reaction, I imagine that Will and Rick didn't ask about "stochastic" because they feared being seen as ignorant. Neither wanted to admit that they "didn't really get the math," to the detriment of their learning and of other lab workers' reflection on their own thinking processes.

\subsubsection{Teaching as Community-Building}

Another way in which undergraduates create learning opportunities for lab members is by serving as mentees, thereby enabling graduate students to learn how to mentor (as Campbell [2003] found that faculty learn how to mentor by advising graduate students). Mentoring is a crucial part of community-building as it guides the socialization of novices while also granting leadership to the mentors, thereby solidifying both groups' double-sided identity as community members. Most studies assume that undergraduates' research mentors are faculty; however, most undergraduate lab workers interact more often with graduate students than with PIs, and they describe graduate students as more approachable than PIs (Dolan and Johnson 
2010). Education scholar Jennifer Good and coauthors (2000) found that undergraduates from underrepresented racial and ethnic groups who served as peer mentors reported benefits to their own learning and professional skills; it's logical to assume that graduate student mentors from underrepresented groups, and perhaps all graduate students, earn similar benefits. Teaching undergraduates also helps graduate students hone their own research mindset and skills (Feldon et al. 2011). Undergraduates give graduate students valuable opportunities to learn how to communicate with and manage others. Dan's postdoc James argued that this is the most important reason to include undergraduates in a research group: "I think [teaching undergraduates] is not very helpful for the project, but it's very helpful for graduate students to learn how to teach the junior students" (interview 2). He believes that undergraduates' presence is more valuable for graduate students' development than for the group's research. Thus, even by doing simple tasks, novices can activate important learning mechanisms for other community members.

Few research communities formally teach experts how to work with non-experts. Accordingly, graduate students learn to work with undergraduates primarily through experience and by observing their PI's approach (Dolan and Johnson 2010). Dan regularly checks in with undergraduate and graduate students during meetings and sometimes coordinates how they work together. In one typical conversation, Dan asked a new undergraduate, Barry, what he was interested in working on. Barry answered that he'd like to analyze data from the group's sensor systems. John asked who was working on that, and graduate student Edward said he was and the work was "straightforward," recommending it for an inexperienced undergraduate. Dan said to Barry, "Edward will be busy with [a project] for a few days but you guys can get together after that" to plan the task and teach Barry to do it. Edward and the other graduate students witnessed how Dan assigned partnerships based on people's interests and relevant expertise. Dan deemed Edward's work with Barry lowerpriority than Edward's other tasks by postponing their meeting; this implies that Edward was in charge of the partnership. In this exchange, Dan modeled how to create research collaborations. He was subtly preparing all the students to someday create these partnerships themselves, through a valuable real-world example provided by an undergraduate. Embedded in this everyday project management conversation was a lesson on how to build a team, especially one that includes novices.

Generally, experienced graduate students perform more effective mentoring and teaching than newer graduate students, suggesting that students acquire or at least improve these community-building skills during graduate school. For example, as senior graduate student Alison helped undergraduate Frank set up an apparatus in Kate's lab, she gently quizzed him about the procedure and accepted or corrected his answers. She created opportunities for him to practice, reinforce, and show off his understanding and for her to assess how well he knows the procedure. In one instance, I asked both of them what results the apparatus produces, and Alison said to Frank, "You can answer that." Frank answered, then asked Alison if he was right. She agreed and elaborated by explaining what can be learned from those results. Alison artfully boosted Frank's double-sided identity as a researcher by inviting him to demonstrate knowledge she knew he had, and then she built on his knowledge by sharing her own. She probably acquired these skills by observing 
Kate's mentorship methods and by working with undergraduates in the lab for several years. In comparison, Kate's graduate student Kenny is about halfway through graduate school and is still learning how to work with undergraduates. In one instance, when undergraduate Gretchen was telling me how a tool worked, Kenny interrupted her to provide the explanation himself. He preferred the role of information-provider to standing back to let the undergraduate demonstrate her knowledge. Gretchen allowed herself to be interrupted, probably in deference to Kenny's higher status as a graduate student and his presumed greater expertise. There could also be a gendered component to this exchange, in that men tend to interrupt more often than women and women tend to acquiesce to being cut off more often than men (Tannen 1994). A graduate student's eagerness to showcase his knowledge over an undergraduate's suggests that he hasn't yet learned how to create space for novices to practice participating in a research community. Luckily, working in Kate's lab alongside undergraduates gives Kenny the opportunity to improve his communication and leadership skills.

\subsubsection{How Broad Education and Outsider Status Encourage Creativity}

Undergraduates bring ideas to research groups from their courses, previous experiences, and hobbies. They are, in a sense, embodied "trading zones" (Galison 1997): they carry knowledge from various fields into their research community, more so than other members due to their ongoing broad education. Dan's graduate student Edward credits this ability to undergraduates' use of social media to follow new trends in technology:

Will and Rick know stuff that are more on the tech news, not on the textbooks ... So they have better ideas ... I start thinking from, like, textbook style, "Is it possible to do?" But they say, "Yeah, it has been done, maybe not feasible in some cases," based on a [specific] project's perspective. It's nice to have those ideas. (interview 4)

Edward rejects Kuhn's and Fleck's portrayals of students as reservoirs of textbook knowledge (except for himself); instead, he admires undergraduates' ability to suggest cutting-edge approaches for the group's research. For example, Edward credits Rick for improving how the group builds their sensor system: "We would just protect [the sensors] somehow, using some casing. We never thought really about 3D printing. But then Rick said, 'Yeah, we can 3D-print,' and the professor said, 'Yeah, that's a good idea'" (interview 4). The undergraduate brought the graduate students a novel idea (as well as the skill to achieve that idea), which they implemented. Dan's approval no doubt contributed to the decision to 3D-print casings, but everyone credits Rick for the idea. It seems that not knowing how the group typically protected sensors enabled Rick to suggest an unconventional way to solve that problem. 
Undergraduates' ideas vary in practicality. Edward recounted Will's innovative solution to a problem with the group's sensor system: "We had this issue with the wifi routers ... Will was saying, 'Why not use powerline data communication [instead]?" (interview 4). Edward was impressed that Will knew about this emerging technology, about which Edward then read several research papers. He was less impressed with the technology's limitations: "It is the trend, but it's not really established and there is a lot of noise in the powerline data." He didn't adopt Will's suggestion; nonetheless, an undergraduate's open-mindedness and broad knowledge influenced a graduate student's learning and decisions.

Undergraduates can serve as a research community's windows on the world beyond the lab, as Rick and Will did above. For example, at a lab meeting Rick presented his idea for a new purpose for the group's sensor systems: monitoring environmental factors that affect public health. His ability to understand the group's systems and situate them in new uses is impressive, reflecting undergraduates' strong connection to fields outside the group's and perhaps also to the "real world" of users because they have not yet become specialized researchers. Rick summarized a paper about a method of monitoring air quality as "It's [our] system on top of a stoplight," thereby using his personal interest in public health to broaden his coworkers' thinking and potentially the impact of their research. Likewise, undergraduate Gretchen's interest in mechanical engineering inspired Kate to think more broadly about her research. Kate told Gretchen about a grant proposal she was writing about alloys. She detailed, in technical terms, the experiments she wanted to include, then added, "I'm trying to make it relevant to the navy" to improve the proposal's chances of being funded. Gretchen asked whether the navy could use these alloys to build engine turbines. Kate answered thoughtfully, "Yes. Oh, maybe I'll put a picture of a ship turbine blade in there." While the PI was thinking about lab-based specifics, the undergraduate asked about general applications, thus creating an opportunity for the PI to consider a new perspective. The PI appreciated this angle and incorporated it in her proposal. Perhaps non-experts can more comfortably play roles of innovators and outsiders than experts can. Without deep knowledge in the field, non-experts draw instead on their wide-ranging experiences and education.

\subsection{Conclusion: Epistemic Exchanges}

Communities depend on newcomers as future members. As those newcomers learn and become socialized, they also make impressive contributions to the community's generation of knowledge, methods, and social norms. For example, undergraduates import concepts and worldviews from other disciplines to lab workers who have deep specialized knowledge and less recent experience with other disciplines. By valuing undergraduates as broadly-educated outsiders, the community benefits from their knowledge and also makes them feel included in the community and its work. In addition, thanks to their role as novices, undergraduates have the privilege and responsibility to improve their own understanding. As a result, they ask questions 
that can inform other members and even inspire them to rethink their assumed knowledge and routine practices. By challenging experts to be aware of how they make knowledge, this reflection encourages more attentive work and more openminded thinking. Undergraduates' laboratory labor is in itself legitimate and valuable; in addition, it creates opportunities for other lab members to learn how to mentor and collaborate. Thus, students provide influential injections of creative and diverse thinking while also enabling social relationships that couldn't happen without them, such as exchanges between experts and novices.

The identities of "novice" and "expert" are relative and context-dependent. Undergraduates are novices in the specific work of a research community, and they are experts at the work and role of learning. Graduate students have (or are acquiring) expertise in a specific field, though they are often novices at collaboration, leadership, and professional communication. PIs are experts in their disciplinary knowledge and professional skills but can be novices in other fields compared to undergraduates who have studied those fields more recently. These identities assign appropriate roles for people to play in different situations, such as question-askervs. answerer, task-focused doer vs. big-picture-focused interpreter, and visionary vs. pragmatist. Lab members shift fluidly between these roles during everyday social interactions, illustrating the concept of double-sided identity as they both perform and are treated as experts or novices in different situations.

This study shows that a technoscientific community is a dynamic network of epistemic exchange, not a purely top-down hierarchy. Community members trade, adapt, and produce knowledge and skills up and down the hierarchy as they change contexts and roles. Focusing on how researchers interact as experts and novices broadens our understanding beyond the work of producing new knowledge to include how communities produce new methods, mindsets, and practitioners. The laboratory is a potent place to observe identity work and community formation in action because it hosts unscripted interactions between various kinds of people around complex tasks. Beyond the lab, these trends continue, though more subtly, in other spaces of scientific interaction, such as publications, conferences, and research governance.

This model of community members' mutual epistemic influence offers a more nuanced and accurate portrayal of today's technoscientific communities. It revises the identity of "novice" to recognize the epistemic value of peripheral wisdom and even inexpertise, as well as of novices' power to call attention to a community's paradigmatic assumptions and actions. This model therefore also implies that communities should include novices, for the benefit of all members. 


\section{References}

Calvert, M.A. 1967. The mechanical engineer in America, 1830-1910: Professional cultures in conflict. Baltimore: Johns Hopkins University Press.

Campbell, R.A. 2003. Preparing the next generation of scientists: The social process of managing students. Social Studies of Science 33 (December): 897-927.

Collins, H., and R. Evans. 2007. Rethinking expertise. Chicago: University of Chicago Press.

Creswell, J. 2007. Qualitative inquiry and research design: Choosing among five approaches. 2nd ed. Thousand Oaks: Sage.

Delamont, S., P. Atkinson, and O. Parry. 2000. The doctoral experience: Success and failure in graduate school. New York: Falmer Press.

Doing, P. 2009. Velvet revolution at the synchrotron. Cambridge, MA: MIT Press.

Dolan, E.L., and D. Johnson. 2010. The undergraduate-postgraduate-faculty triad: Unique functions and tensions associated with undergraduate research experiences at research universities. Cell Biology Education 9: 543-553.

Dolan, E., and D. Johnson. 2009. Toward a holistic view of undergraduate research experiences: An exploratory study of impact on graduate/postdoctoral mentors. Journal of Science Education and Technology 18 (6): 487-500.

Duschinsky, R. 2012. Tabula rasa and human nature. Philosophy 87 (04): 509-529.

Feldon, D.F., J. Peugh, B.E. Timmerman, M.A. Maher, M. Hurst, D. Strickland, and C. Stiegelmeyer. 2011. Graduate students' teaching experiences improve their methodological research skills. Science 333 (6045): 1037-1039.

Felt, U., ed. 2009. Knowing and living in academic research: Convergence and heterogeneity in research cultures in the European context. Prague: Institute of Sociology of the Academy of Sciences of the Czech Republic.

Felt, U., J. Igelsböck, A. Schikowitz, and T. Völker. 2013. Growing into what? The (un-)disciplined socialisation of early stage researchers in transdisciplinary research. Higher Education 65 (4): 511-524.

Fleck, L. 1979. Genesis and development of a scientific fact. Chicago: University of Chicago Press.

Fujimura, J.H. 1996. Crafting science: A sociohistory of the quest for the genetics of cancer. Cambridge, MA: Harvard University Press.

Galison, P. 1997. Image and logic: A material culture of microphysics. Chicago: University of Chicago Press.

Good, J.M., G. Halpin, and G. Halpin. 2000. A promising prospect for minority retention: Students becoming peer mentors. The Journal of Negro Education 69 (4): 375-383.

Gorman, M.E. 2002. Types of knowledge and their roles in technology transfer. The Journal of Technology Transfer 27 (3): 219-231.

Hackett, E.J. 2005. Essential tensions: Identity, control, and risk in research. Social Studies of Science 35 (5): 787-826.

Hakkarainen, K.P., T. Palonen, S. Paavola, and E. Lehtinen. 2004. Communities of networked expertise: Professional and educational perspectives. Amsterdam: Elsevier.

Holland, D.C., W. Lachiocotte, D. Skinner, and C. Cain. 1998. Identity and agency in cultural worlds. Cambridge, MA: Harvard University Press.

Jones, M.G., and L. Brader-Araje. 2002. The impact of constructivism on education: Language, discourse, and meaning. American Communication Journal 5 (3): 1-10.

Kaiser, D., ed. 2005. Pedagogy and the practice of science: Historical and contemporary perspectives. Cambridge, MA: MIT Press.

Kuhn, T.S. 1996. The structure of scientific revolutions. 3rd ed. Chicago: University of Chicago Press.

Larivière, V. 2012. On the shoulders of students? The contribution of PhD students to the advancement of knowledge. Scientometrics 90 (2): 463-481.

Laudel, G., and J. Glaser. 2008. From apprentice to colleague: The metamorphosis of early career researchers. Higher Education 55 (3): 387-406. 
Lave, J., and E. Wenger. 1991. Situated learning: Legitimate peripheral participation. Cambridge: Cambridge University Press.

Magnusson, S., J. Krajcik, and H. Borko. 1993. Nature, sources, and development of pedagogical content knowledge for science teaching. Examining Pedagogical Content Knowledge: 95-132.

Mody, C.C.M., and D. Kaiser. 2008. Scientific training and the creation of scientific knowledge. In The handbook of science and technology studies, ed. E.J. Hackett, O. Amsterdamska, M. Lynch, and J. Wajcman, 377-402. Cambridge, MA: MIT Press.

National Academies of Sciences, Engineering, and Medicine. 2017. Undergraduate research experiences for STEM students: Successes, challenges, and opportunities. Washington, D.C: National Academies Press.

Schön, D.A. 1987. Educating the reflective practitioner: Toward a new design for teaching and learning in the professions. San Francisco: Jossey-Bass.

Stevens, R., K. O'Connor, L. Garrison, A. Jocuns, and D.M. Amos. 2008. Becoming an engineer: Toward a three-dimensional view of engineering learning. Journal of Engineering Education (July): 355-368.

Tannen, D. 1994. Talking from 9 to 5: How women's and men's conversational styles affect who gets heard, who gets credit, and what gets done at work. New York: William Morrow and Company, Inc.

Traweek, S. 1988. Beamtimes and lifetimes: The world of high energy physicists. Cambridge, MA: Harvard University Press.

Walford, G. 1981. Classification and framing in postgraduate education. Studies in Higher Education 6 (2): 147-158.

. 1983. Postgraduate education and the student's contribution to research. British Journal of Sociology of Education 4 (3): 241-254.

Wegner, D.M. 1986. Transactive memory: A contemporary analysis of the group mind. In Theories of group behavior, ed. B. Mullen and G.R. Goethals, 185-208. New York: Springer.

Wenger, E. 1998. Communities of practice: Learning, meaning, and identity. Cambridge: Cambridge University Press.

Wilson, S. M., and P. L. Peterson. 2006. Theories of learning and teaching: What do they mean for educators? Best practices, new research. Working paper for the National Education Association.

Wylie, A. 2015a. A plurality of pluralisms: Collaborative practice. In Objectivity in science, ed. F. Padovani, 189-210. Springer International Publishing.

Wylie, C.D. 2015b. "The artist's piece is already in the stone": Constructing creativity in paleontology laboratories. Social Studies of Science 45 (1): 31-55.

2016. Invisibility as a mechanism of social ordering: Defining groups among laboratory workers. In Invisible labour, ed. J. Bangham and J. Kaplan. Berlin: Max Planck Institute for the History of Science. Retrieved from https://www.mpiwg-berlin.mpg.de/sites/default/files/ migrated/book_invisibility_and_labour_in_the_human_sciences_preprint_.pdf.

. 2018a. Trust in technicians in paleontology laboratories. Science, Technology and Human Values 43 (2): 324-348.

—. 2018b. "I just love research": Beliefs about what makes researchers successful. Social Epistemology 32 (4): 262-271.

Wylie, C.D., and M.E. Gorman. 2018. Learning in laboratories: How undergraduates participate in engineering research. In Proceedings of the American Society for Engineering Education. Salt Lake City. https://peer.asee.org/29966.

Wylie, C.D. 2019. Socialization through stories of disaster in engineering laboratories. Social Studies of Science 49 (6): 817-838.

Wylie, C.D., S.J. Kim, I. Linville, and A. Campo. 2019. Graduate/undergraduate partnerships (GradUP): How graduate and undergraduate students learn research skills together. In Proceedings of the American Society for Engineering Education. FL: Tampa. https://peer.asee.org/ 32879.

Yoder, B. L. 2016. Engineering by the numbers. American Society for Engineering Education. Retrieved from https://www.asee.org/documents/papers-and-publications/publications/collegeprofiles/16Profile-Front-Section.pdf. 
Open Access This chapter is licensed under the terms of the Creative Commons Attribution 4.0 International License (http://creativecommons.org/licenses/by/4.0/), which permits use, sharing, adaptation, distribution and reproduction in any medium or format, as long as you give appropriate credit to the original author(s) and the source, provide a link to the Creative Commons license and indicate if changes were made.

The images or other third party material in this chapter are included in the chapter's Creative Commons license, unless indicated otherwise in a credit line to the material. If material is not included in the chapter's Creative Commons license and your intended use is not permitted by statutory regulation or exceeds the permitted use, you will need to obtain permission directly from the copyright holder. 